\title{
PENGEMBANGAN DESA SUMBER HARAPAN SEBAGAI DESA SENTRA TENUN SONGKET DI KABUPATEN SAMBAS
}

\section{DEVELOPMENT OF SUMBER HARAPAN VILLAGE AS A SONGKET CENTER VILLAGE IN SAMBAS DISTRICT}

\author{
Suhendra $^{\# 1}$, Andri Hidayat ${ }^{* 2}$, Feby Nopriandy ${ }^{\# 3}$, Budi Setiawan ${ }^{\# 4}$ \\ 1,3,4 Jurusan Teknik Mesin, Politeknik Negeri Sambas \\ ${ }^{2}$ Jurusan Manajemen Informatika, Politeknik Negeri Sambas \\ Jl. Raya Sejangkung, Sambas \\ 1aka.suhendra@yahoo.com
}

\begin{abstract}
Abstrak
Desa Sumber Harapan dikenal sebagai desa wisata budaya khususnya kerajinan tenun songket. Desa ini terletak di Kecamatan Sambas, Kabupaten Sambas Propinsi Kalimantan Barat. Letak geografis Kabupaten Sambas yang berbatasan langsung dengan Negara Malaysia sangat mempengaruhi kondisi sosial ekonomi masyarakat desa Sumber Harapan. Permasalahan prioritas yang dihadapi pengrajin tenun songket Sambas adalah proses produksi, pengemasan, promosi dan pemasaran. Tujuan yang ingin dicapai dalam kegiatan pengabdian di desa Sumber Harapan adalah memperbaiki proses produksi tenun songket, memberikan bantuan pengemasan (packing) yang lebih baik, mempromosikan produk dalam berbagai kegiatan dan memasarkan kain tenun songket Sambas melalui pameran produk tenun. Mitra dalam kegiatan pengabdian di desa Sumber Harapan terdiri dari Koperasi Rantai Mawar beranggotakan, kelompok tenun Sumber Rezeki, kelompok tenun Cual Mandiri dan karang taruna Lestari desa Sumber Harapan.Kegiatan pengabdian yang dilakukan di desa Sumber Harapan adalah bantuan mesin penggulung benang tenun beserta pelatihan cara pengoperasian dan perawatannya, pelatihan desain grafis untuk kemasan, bantuan kotak kemasan produk tenun, promosi dan pemasaran melalui kegiatan pameran produk tenun dan pelatihan sablon. Hasil kegiatan pengabdian menunjukkan bahwa terjadi peningkatan daya saing produk, perbaikan tata nilai masyarakat, peningkatan penerapan Iptek di desa dan peningkatan SDM masyarakat. Pengukuran hasil evaluasi kegiatan dilakukan melalui kuisioner yang diisi oleh mitra, peningkatan harga jual produk dan jumlah transaksi yang dilakukan terhadap produk tenun.
\end{abstract}

Kata Kunci — Kain, kerajinan, tenun songket

Abstract

Sumber Harapan village is known as a cultural tourism village especially songket weaving crafts. This village is located in Sambas District, Sambas Regency, West Kalimantan Province. The geographical location of Sambas Regency, which borders directly with the State of Malaysia, greatly affects the socio-economic conditions of Sumber Harapan village communities. The priority problems faced by Sambas songket weaving craftsmen are the production, packaging, promotion and marketing processes. The objectives to be achieved in the service activities in Sumber Harapan village are to improve the production process of songket weaving, provide better packaging assistance, promote products in various activities and market the Sambas songket woven fabric through the weaving product exhibition. Partners in community service activities in Sumber Harapan village consist of the Mawar Chain Cooperative consisting of Sumber Rezeki weaving group, Cual Mandiri weaving group and Lestari Karanguna Youth Organization Sumber Harapan village. Community service activities carried out in Sumber Harapan village are assistance of weaving yarn rolling machine and training on how to operate and its maintenance, graphic design training for packaging, packaging assistance for weaving product boxes, promotion and marketing through weaving product exhibition and screen printing training. The results of the community service activities show that there is an increase in product competitiveness, improvement of community values, an increase in the application of science and technology in the village, and an increase in community human resources. Measurement of the results of the evaluation of activities is carried out through a questionnaire filled out by partners, an increase in the selling price of the product and the number of transactions carried out on woven products.

Keywords - Fabric, handicraft, songket weaving

\section{PENDAHULUAN}

Seni budaya Indonesia yang cukup terkenal di luar negeri adalah seni kerajinan seperti kerajinan ukir, anyaman, batik, tenun, wayang dan kemarik. Teknik bertenun sudah sejak lama dikenal oleh bangsa Indonesia yang dibuktikan dengan penemuan tembikar pada periode neolitik berupa kain tenun kasar dan beberapa bagian kain tenun lainnya (Soesandireja, 2015). Hal tersebut menggambarkan bahwa nenek moyang kita telah lama mengenal budaya khususnya tradisi bertenun yang memiliki nilai seni dan masih bertahan hingga era modern sekarang ini. 
Desa Sumber Harapan merupakan desa wisata budaya tenun di Kabupaten Sambas. Desa ini terkenal sebagai sentra kerajinan kain tenun songket Sambas (Suhendra, dkk. 2018). Menurut BPS Kab. Sambas (2016), desa Sumber Harapan memiliki luas wilayah 22,56 $\mathrm{km}^{2}$ terdiri dari 3 Dusun yaitu Dusun Semberang I, Semberang II dan Solor Medan. Berpenduduk sekitar 2.616 jiwa, sebagian besar mata pencaharian penduduk desa Sumber Harapan adalah bertani dan wiraswasta khususnya sebagai pengrajin tenun songket Sambas.

Kondisi geografis Kabupaten Sambas yang berbatasan langsung dengan Negara Malaysia serta berdekatan dengan Brunei menyebabkan banyak warga Sambas bekerja disana. Selain itu, banyak pengrajin tenun dari Sambas yang ditawarkan untuk bekerja sebagai penenun di Sarawak (Malaysia) dan Brunei dengan gaji yang lebih menjanjikan. Hal ini menyebabkan banyak ditemui motif yang mirip antara kain tenun songket dari Sambas, Sarawak (Malaysia) dan Brunei.

Kegiatan bertenun umumnya hanya dilakukan oleh ibu-ibu, dan kurang diminati kalangan muda. Pekerjaan menjadi pengrajin tenun kurang diminati karena penghasilan yang diperoleh dari hasil tenun kurang menjanjikan. Berdasarkan data Dinas Koperasi UMKM Perindustrian dan Perdagangan Kabupaten Sambas tahun 2013, jumlah pengrajin tenun pada data daftar industri kecil menengah non formal hanya tinggal 256 orang. Berkurangnya minat masyarakat terhadap tenun songket merupakan sesuatu yang sangat mengkhawatirkan karena tenun songket merupakan produk yang memiliki nilai budaya tinggi, sehingga sudah selayaknya hasil kerajinan tenun songket Sambas harus dijaga dan dilestarikan untuk menjaga keberlanjutannya.

Mitra dalam kegiatan pengabdian di desa Sumber Harapan terdiri dari Koperasi Rantai Mawar beranggotakan 32 orang, kelompok tenun Sumber Rezeki beranggotakan 50 orang, kelompok tenun Cual Mandiri beranggotakan 10 orang dan karang taruna Lestari desa Sumber Harapan.

Berdasarkan hasil survey lapangan melalui diskusi langsung dengan mitra kegiatan pengabdian meliputi para pengrajin tenun yang tergabung dalam Koperasi dan UMKM, permasalahan prioritas yang dihadapi pengrajin tenun songket Sambas adalah proses produksi, promosi dan pemasaran.

Menurut Suhendra dkk. (2018), kain tenun songket Sambas masih diproduksi menggunakan alat tenun tradisional yang terbuat dari kayu. Waktu yang dibutuhkan untuk membuat kain tenun songket Sambas sekitar 2 sampai 4 minggu tergantung tingkat kerumitan motif. Harga jual kain tenun songket berkisar antara Rp. 900.000 - Rp. 1.200.000,-. Kain tenun songket yang dijual umumnya hanya dikemas dengan plastik biasa. Sistem penjualan hanya dilakukan dengan membuka tempat penjualan di rumah atau di tempat tertentu, dimana pembeli akan datang ke lokasi untuk melihat kain secara langsung selanjutnya melakukan transaksi.

Melalui program pengabdian ini tim pelaksana berupaya mengatasi berbagai permasalahan yang dihadapi para pengrajin tenun songket Sambas di desa Sumber Harapan melalui pengembangan alat tenun tradisional menjadi alat tenun semi mekanis, membantu pengemasan produk tenun, mempromosikan dan memasarkan produk tenun.

Pengembangan alat tenun tradisional dapat memudahkan pengrajin tenun dalam proses menggulung benang tenun. Pengembangan sistem pengemasan dapat memberikan tampilan yang menarik, serta memberikan nilai estetika yang lebih baik pada produk sehingga kain tenun songket dapat dijual dengan harga yang lebih tinggi. Promosi diperlukan untuk lebih mengenalkan kain songket Sambas ke luar daerah

\section{TARGET DAN LUARAN}

Target dan luaran dalam kegiatan pengabdian ini adalah dihasilkannya publikasi pada jurnal nasional pengabdian serta publikasi pada media cetak/online. Target lainnnya adalah meningkatnya nilai tambah barang, penggunaan IT dan penerapan ipteks serta menghasilkan inovasi rekayasa mesin penggulung benang otomatis untuk membantu proses produksi tenun songket.

\section{METODE PELAKSANAAN}

Metode pelaksanaan kegiatan pengabdian dalam upaya menyelesaikan persoalan yang dihadapi pengrajin tenun songket Sambas di desa Sumber Harapan dapat dilihat dalam diagram alir berikut.

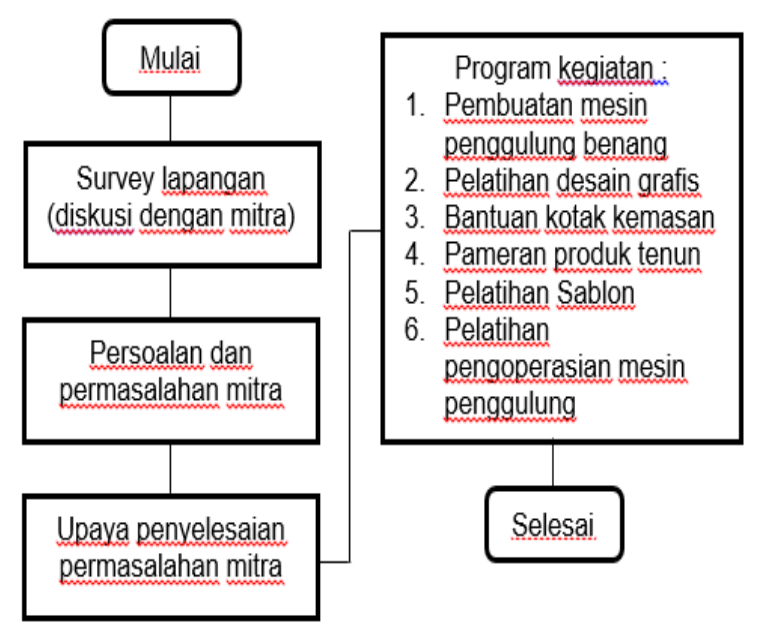

Gambar 1. Diagram alir metode pelaksanaan pengabdian 


\section{HASIL DAN PEMBAHASAN}

Kegiatan pengabdian yang dilaksanakan di desa Sumber Harapan meliputi beberapa tahapan kegiatan meliputi :

\section{A. Sosialisasi Kegiatan}

Tahap awal kegiatan pengabdian di desa Sumber Harapan adalah mensosialisasikan kegiatan yang akan dilaksanakan kepada mitra. Perwakilan mitra diundang untuk diberikan penjelasan tentang program dan rencana kegiatan yang akan dilaksanakan. Diskusi antara mitra dan tim pelaksana dilakukan untuk mematangkan rencana yang telah disusun sebelumnya.

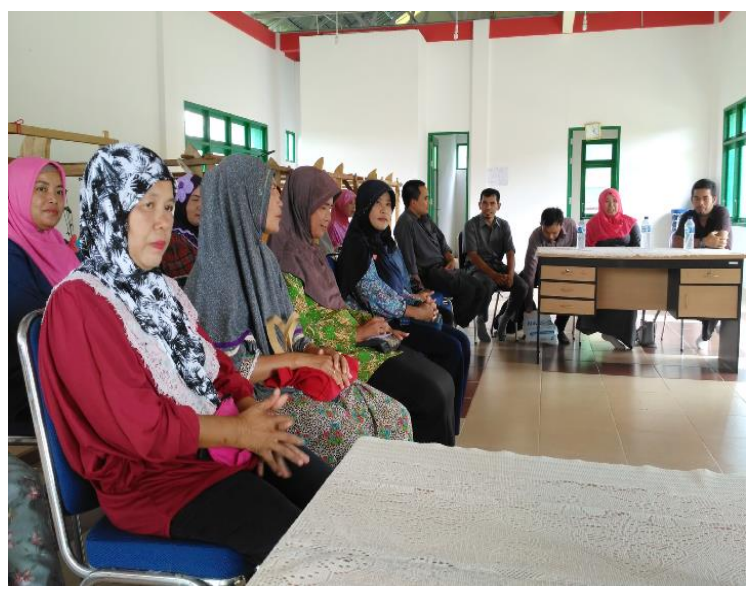

Gambar 2. Sosialisasi program kegiatan PPDM pada mitra

\section{A. Pembuatan Mesin Penggulung Benang}

Mesin penggulung benang dibuat menggunakan motor listrik DC 12 Volt sebagai penggeraknya. Kecepatan putar yang dihasilkan dari motor listrik dapat diatur dengan memutar tombol yang berada pada kontrol panel. Pengaturan kecepatan berfungsi agar proses penggulungan benang dapat dikontrol. Mesin penggulung dilengkapi dengan kopling untuk untuk menghindari benang putus pada saat penggulungan benang berhenti mendadak.

Tahapan dalam pembuatan mesin penggulung benang meliputi tahap mempersiapkan alat dan bahan yang diperlukan, memotong dan mengebor pelat untuk dudukan mesin penggulung, membubut poros, membuat pola, memotong pelat aluminium menyesuaikan pola, membentuk pelat yang sudah dipotong, menyambung dudukan kaki dengan cara dilas, merapikan hasil pengelasan, melakukan pengecatan, merakit komponen dan melakukan uji fungsional terhadap mesin penggulung.

Hasil uji fungsional menunjukkan bahwa mesin penggulung benang dapat berfungsi dengan baik untuk menggulung benang. Kopling pada mesin penggulung berfungsi dengan baik untuk memutus dan menghubungkan putaran motor penggerak.
Putaran mesin penggulung akan berhenti saat penggulungan benang dihentikan seketika.
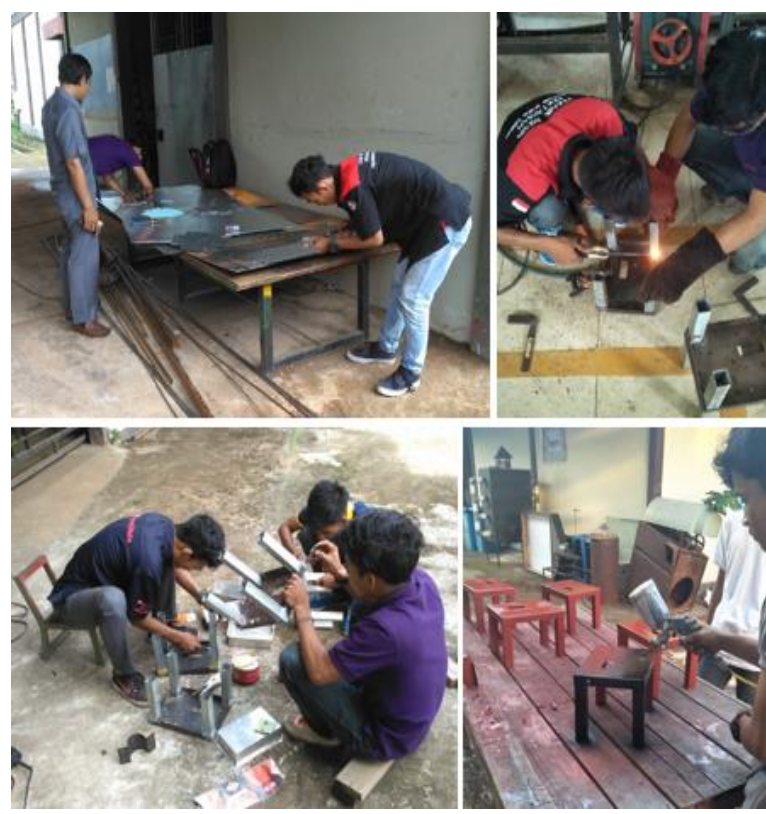

Gambar 3. Proses pembuatan mesin penggulung benang

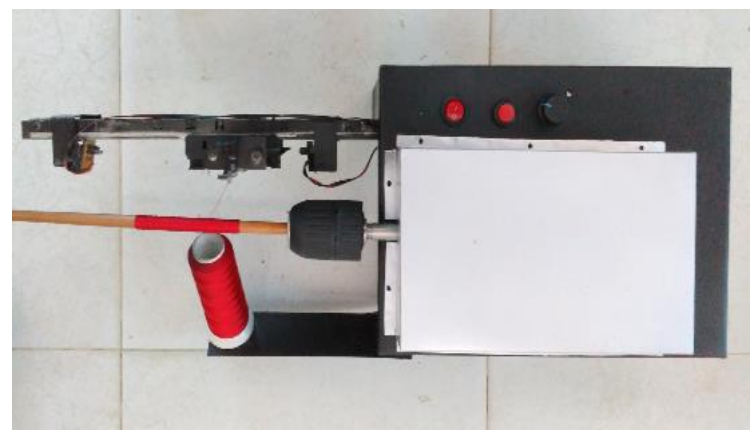

Gambar 4. Mesin penggulung benang

\section{B. Pelatihan Desain Grafis untuk Kemasan}

Pelatihan desain grafis bertujuan untuk melatih mitra dalam mendesain kemasan dan brosur berbagai produk tenun. Software yang digunakan untuk pelatihan adalah Coreldraw Graphics-Suite-X7. Pelatihan desain grafis terdiri dari materi pelatihan tingkat dasar dan tingkat menengah. Mitra diajarkan tentang dasar-dasar Coreldraw, membuat bentuk, memberi warna, editing bentuk dan lain sebagainya.

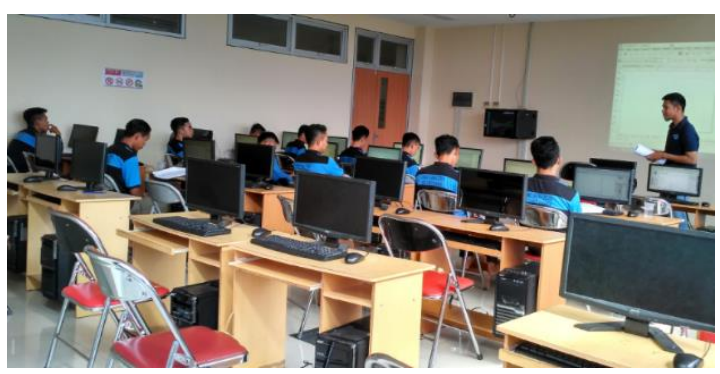

Gambar 5. Pelatihan desain grafis untuk brosur dan kemasan 
Evaluasi kegiatan dilakukan dengan memberikan kuisioner terhadap 12 peserta pelatihan. Hasil kuisioner menunjukkan bahwa terdapat peningkatan kemampuan mitra yang diukur dari sebelum pelatihan dan setelah pelatihan selesai dilakukan.

Tabel 1. Evaluasi kegiatan pelatihan desain grafis untuk kemasan

\begin{tabular}{lcccc}
\hline Pelaksanaan & $\begin{array}{c}\text { Tidak } \\
\text { bisa }\end{array}$ & $\begin{array}{c}\text { Kuran } \\
\text { bisa }\end{array}$ & $\begin{array}{c}\text { Cukup } \\
\text { bisa }\end{array}$ & Bisa \\
\hline $\begin{array}{l}\text { Sebelum } \\
\text { pelatihan }\end{array}$ & $66,7 \%$ & $25,0 \%$ & $8,3 \%$ & $0,0 \%$ \\
\hline $\begin{array}{l}\text { Setelah } \\
\text { pelatihan }\end{array}$ & $0,0 \%$ & $8,3 \%$ & $33,3 \%$ & $58,3 \%$ \\
\hline
\end{tabular}

\section{Bantuan Kotak Kemasan untuk Produk}

Hasil desain kemasan terbaik yang dibuat para mitra selanjutnya dipilih untuk dijadikan tutup kotak kemasan kain tenun. Tambahan kemasan pada produk tenun dapat menambah nilai estetika produk tenun sehingga produk menjadi barang eksklusif yang memiliki nilai jual tinggi. Harga kain tenun yang telah diberi kemasan dapat meningkat menjadi Rp. 50.000 - Rp. 100.00,- dari harga sebelum diberi kemasan.

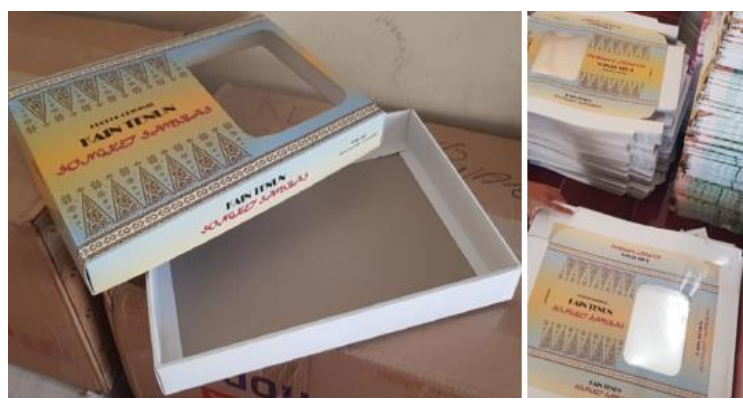

Gambar 6. Kotak kemasan produk tenun

Kotak kemasan didesain berukuran panjang $40 \mathrm{~cm}$ dan lebar $28 \mathrm{~cm}$ yang dapat digunakan untuk menyimpan kain tenun atau satu set perlengkapan tenun seperti kain, selendang dan sabuk. Bagian tutup atas kemasan, terdapat lubang yang dilapisi plastik transparan berukuran $20 \times 16 \mathrm{~cm}$ berfungsi untuk melihat motif kain dari luar. Motif kemasan berupa pucuk rebung yang dihiasi oleh berbagai motif tabur. Pada tutup atas kemasan terdapat tulisan "Produk Original Kain Tenun Songket Sambas", dan pada bagian samping terdapat tulisan "PPDM 2018 Politeknik Negeri Sambas - Kemenristek DIKTI".

\section{Pameran Produk Tenun}

Pameran yang diikuti dalam program pengabdian ini adalah pameran yang diadakan oleh Pemerintah Kabupaten Sambas dalam rangka ulang tahun pemindahan ibukota kabupaten dari kota Singkawang ke kota Sambas yang diadakan di halaman kantor Pemerintahan Kabupaten Sambas. Pameran dilaksanakan selama 11 hari yaitu dari tanggal 27 Juli sampai 6 Agustus 2018. Pameran diikuti oleh berbagai instansi dan dinas dengan menampilkan berbagai produk unggulan masing-masing.

Tujuan mengikuti pameran ini adalah untuk mengenalkan program pengabdian serta mempromosikan dan memasarkan produk-produk hasil kerajinan tenun dari desa Sumber Harapan sebagai mitra kegiatan. Produk hasil kerajinan yang dipamerkan antara lain adalah tanjak, kopiah, kain, sal, selendang, sabuk, tempat tisu, tas, dompet dan lainlain. Kegiatan pameran cukup memberikan dampak positif terhadap peningkatan penjualan mitra.

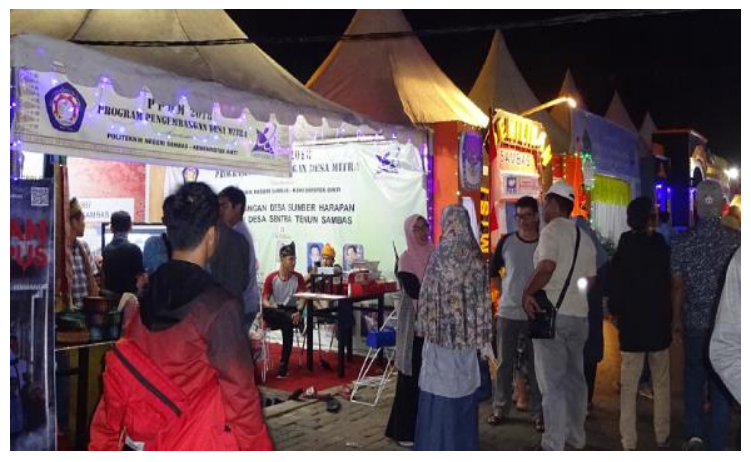

Gambar 7. Kegiatan pameran produk tenun

Evaluasi kegiatan dilakukan dengan melihat jenis produk yang paling diminati pembeli dan banyaknya produk yang terjual. Data lengkap hasil perjualan produk tenun selama pameran dapat dilihat pada Tabel 2.

Tabel 2. Hasil perjualan produk tenun selama pameran pembangunan

\begin{tabular}{lclc}
\hline Jenis Produk & $\begin{array}{c}\text { Jumlah } \\
\text { terjual }\end{array}$ & Jenis Produk & $\begin{array}{c}\text { Jumlah } \\
\text { terjual }\end{array}$ \\
\hline Kopiah & 22 & Lis baju & 10 \\
Tanjak & 20 & Kain & 1 \\
Tempat tisu & 3 & Selendang & 1 \\
Syal & 9 & Tas & 3 \\
Bahan baju & 2 & & \\
\hline
\end{tabular}

\section{E. Pelatihan Sablon}

Pelatihan sablon dalam kegiatan pengabdian ini diikuti oleh karang taruna lestari. Pelatihan sablon meliputi pelatihan pembuatan film sablon, pelatihan sablon 1 warna dan pelatihan sablon multi warna. Kegiatan pelatihan dilaksanakan pada malam hari agar proses pembuatan film dan proses penyablonan dapat berlangsung dengan baik. Dalam pelatihan ini, mitra diajarkan teknik membuat film sablon, teknik penggunaan peralatan sablon, sistem pencahayaan pada proses sablon, pencampuran bahan-bahan sablon, pembersihan screen sablon dan proses penyablonan. 


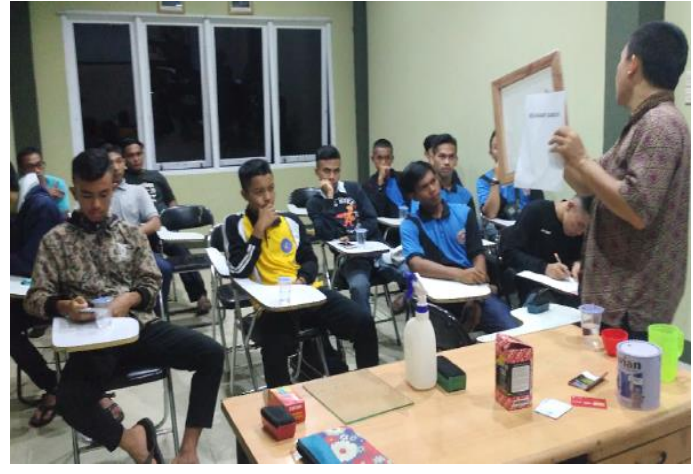

Gambar 8. Kegiatan pelatihan sablon

Evaluasi kegiatan dilakukan dengan memberikan kuisioner terhadap 13 peserta pelatihan. Hasil kuisioner menunjukkan bahwa terdapat peningkatan kemampuan mitra yang diukur dari sebelum pelatihan dan setelah pelatihan selesai dilakukan.

TABEL 3. EVALUASI KEGIATAN PELATIHAN PEMBUTAN FILM

\begin{tabular}{lcccc}
\hline \multicolumn{5}{c}{ PEMBUTAN FILM } \\
Pelaksanaan & $\begin{array}{c}\text { Tidak } \\
\text { bisa }\end{array}$ & $\begin{array}{c}\text { Kuran } \\
\text { bisa }\end{array}$ & $\begin{array}{c}\text { Cuku } \\
\text { bisa }\end{array}$ & Bisa \\
\hline $\begin{array}{l}\text { Sebelum } \\
\text { pelatihan }\end{array}$ & $\begin{array}{c}84,6 \\
\%\end{array}$ & $15,4 \%$ & $0,0 \%$ & $0,0 \%$ \\
\hline Setelah pelatihan & $\begin{array}{c}15,4 \\
\%\end{array}$ & $38,5 \%$ & $\begin{array}{c}30,8 \\
\%\end{array}$ & $\begin{array}{c}15,4 \\
\%\end{array}$ \\
\hline
\end{tabular}

TABEL 4. EVALUASI KEGIATAN PELATIHAN SABLON 1 WARNA

\begin{tabular}{lcccc}
\hline \multicolumn{1}{c}{ Pelaksanaan } & $\begin{array}{c}\text { Tidak } \\
\text { bisa }\end{array}$ & $\begin{array}{c}\text { Kuran } \\
\text { bisa }\end{array}$ & $\begin{array}{c}\text { Cuku } \\
\text { bisa }\end{array}$ & Bisa \\
\hline $\begin{array}{l}\text { Sebelum } \\
\text { pelatihan }\end{array}$ & $\begin{array}{c}69,2 \\
\%\end{array}$ & $23,1 \%$ & $7,7 \%$ & $0,0 \%$ \\
\hline Setelah pelatihan & $0,0 \%$ & $0,0 \%$ & $\begin{array}{c}46,2 \\
\%\end{array}$ & $\begin{array}{c}53,8 \\
\%\end{array}$ \\
\hline
\end{tabular}

TABEL 5. EVALUASI KEGIATAN PELATIHAN SABLON MULTI

\begin{tabular}{lcccc}
\multicolumn{5}{c}{ WARNA } \\
\hline Pelaksanaan & $\begin{array}{c}\text { Tidak } \\
\text { bisa }\end{array}$ & $\begin{array}{c}\text { Kuran } \\
\text { bisa }\end{array}$ & $\begin{array}{c}\text { Cuku } \\
\text { bisa }\end{array}$ & Bisa \\
\hline $\begin{array}{l}\text { Sebelum } \\
\text { pelatihan }\end{array}$ & $\begin{array}{c}76,9 \\
\%\end{array}$ & $15,4 \%$ & $7,7 \%$ & $0,0 \%$ \\
\hline Setelah pelatihan & $7,7 \%$ & $23,1 \%$ & $\begin{array}{c}30,8 \\
\%\end{array}$ & $\begin{array}{c}38,5 \\
\%\end{array}$ \\
\hline
\end{tabular}

\section{F. Pelatihan Pengoperasian dan Perawatan Mesin} Penggulung Benang

Mesin penggulung benang didesain memiliki kecepatan yang dapat diatur putarannya, sistem penyusunan benang bergerak secara otomatis, dapat digunakan untuk menggulung 2 benang sekaligus, dan berhenti secara otomatis jika ukuran gulungan sudah mencapai ukuran yang diinginkan. Sebelum mesin penggulung diserahkan, dilakukan pelatihan tentang tata cara pengoperasian dan perawatan mesin penggulung.

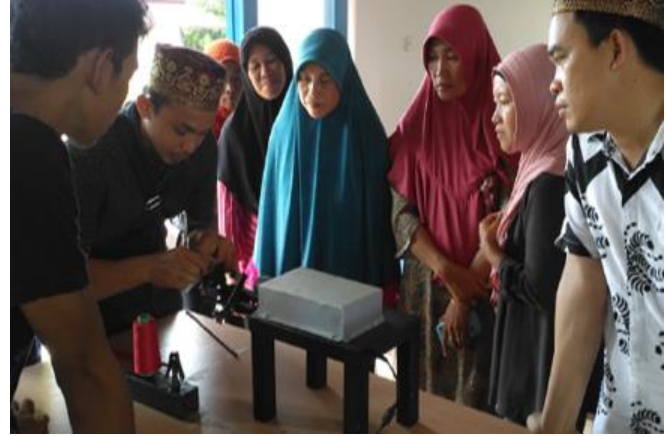

Gambar 9. Pelatihan pengoperasian dan perawatan mesin penggulung benang

\section{G. Serah Terima Barang}

Kegiatan akhir dalam pelaksanaan pengabdian PPDM adalah serah terima barang kepada mitra. Barang yang diserahkan antara lain adalah 3 unit alat tenun beserta kelengkapannya, 750 buah kotak kemasan, 3 unit mesin penggulung benang otomatis, 2 unit meja sablon, 2 unit box sablon, 2 unit perlengkapan pencahayaan sablon dan kelengkapan peralatan sablon.

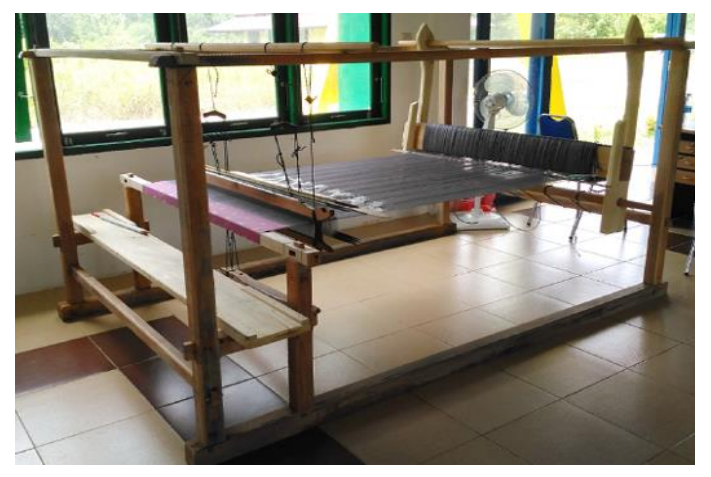

Gambar 10. Alat tenun dan kelengkapannya yang diserahkan

Serah terima barang disaksikan langsung oleh Direktur Politeknik Negeri Sambas, Kepala desa Sumber Harapan, Wakil Direktur III, perwakilan P3M Politeknik Negeri Sambas dan masing-masing mitra. Sebelum pelaksanaan serah terima, dilakukan diskusi antara pengrajin tenun dengan tim dari Politeknik Negeri Sambas untuk memberikan masukan terhadap kegiatan yang telah dilaksanakan agar kedepannya menjadi lebih baik.

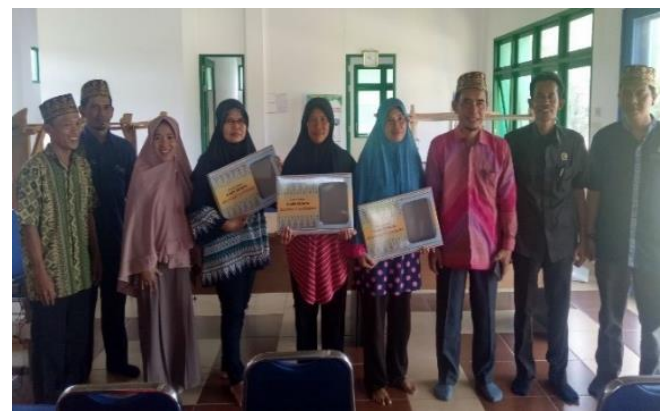

Gambar 11. Kegiatan serah terima barang 


\section{KESIMPULAN}

- Hasil kegiatan menunjukkan bahwa terjadi peningkatan daya saing produk, perbaikan tata nilai masyarakat, peningkatan penerapan Iptek di desa dan peningkatan SDM masyarakat.

- Pengukuran hasil evaluasi kegiatan dilakukan melalui kuisioner yang diisi oleh mitra

- Luaran kegiatan PPDM yang telah dihasilkan adalah publikasi kegiatan pada surat kabar AP Post dipublikasi pada tanggal 4 Agustus 2018, pemakalah dan prosiding pada Seminar Nasional Senasif 2 di Fakultas Teknologi Informasi, Universitas Merdeka Malang pada tanggal 9 Agustus 2018, modul Pelatihan desain grafis, draf buku tenun ber-ISBN untuk diterbitkan, mesin penggulung benang otomatis dan alat tenun disertai kelengkapannya.

\section{UCAPAN TERIMA KASIH}

Penghargaan dan ucapan terima kasih ini disampaikan kepada pihak yang telah membantu pelaksanaan kegiatan pengabdian di desa Sumber Harapan antara lain kepada :

- Kementerian Riset, Teknologi dan Pendidikan Tinggi

- Direktur Politeknik Negeri Sambas

- Semua pihak yang terlibat dalam kegiatan pengabdian.

\section{DAFTAR PUSTAKA}

[1] BPS Kabupaten Sambas. 2016. Kecamatan Sambas Dalam Angka 2016

[2] Dinas Koperasi UMKM Perindustrian dan Perdagangan Kabupaten Sambas tahun 2013

[3] Soesandireja. 2015. Kain Songket; Asal Mula, Jenis, dan Maknanya, http://www.wacana.co

[4] Suhendra, Feby Nopriandy, Andri Hidayat, Budi Setiawan dan Munandar. 2018. Peningkatan Daya Saing Pengrajin Tenun Songket di Desa Sumber Harapan, Sambas. Prosiding Seminar Nasional Senasif 2. Hal. 1539-1545 